\title{
Knowledge about risk factors for falls and practice about fall prevention in older adults
} among physiotherapists in Nigeria.

\section{ABSTRACT}

\section{Background and Objective}

Falling is a major health concern that has contributed significantly to older people's injury and loss of life worldwide, warranting the development of fall prevention strategies, the success of which has been attributed to the levels of knowledge and practice about fall prevention among physiotherapists and other health professionals. The objective of this study was to determine the self-reported levels of knowledge on risk factors of fall and practices about fall prevention in older adults among physiotherapists in Nigeria.

\section{Methods}

Physiotherapists ( $N=237$ ) recruited from the six geopolitical zones of Nigeria completed a threepart structured questionnaire that asked questions about risk factors for fall and common practices for fall prevention using a 5-point rated Likert scale. Data were analyzed using descriptive analysis, Chi-Square and Kruskal-Wallis tests.

\section{Results}

Among physiotherapists in Nigeria, $89 \%$ rated their level of knowledge about preventing falls among older adults as high, and $64 \%$ of them rated their level of practice on this topic as high. Among the individual items that measured knowledge, $40 \%$ of the participants reported a moderate level of knowledge about multiple medications as a risk factor for falls. Fifty percent of the participants reported a low level of practice of referral to other healthcare professionals, 
while $40 \%$ and $41 \%$ reported a moderate level of practice on documenting risk factors and treatment plans, respectively. There was no association between age, gender, or years of practice with levels of knowledge or practice.

\section{Conclusion}

This study suggests that physiotherapists in Nigeria have adequate knowledge and practice for fall prevention in older adults. However, there are potential gaps in knowledge of risk factors, documentation and referrals to other professions that may be addressed through developing context-specific fall prevention clinical guidelines for practice in Nigeria.

Keywords: Accidental Falls, Elderly People, Nigeria, Physical Therapists, Professional Practice. 


\section{INTRODUCTION}

Globally, the ageing population is increasing, and it has been projected that the number of adults aged 60 and above will triple in 35 years in Nigeria, from 8,158,000 in 2015 to 26,417,000 in 2050 (United Nations Population Division, 2015). Consequently, conditions associated with old age are also likely to increase in prevalence. Many conditions that have higher prevalence in older adults (such as stroke, Parkinson's, osteoarthritis, rheumatoid arthritis, and dementia) are associated with higher incidence of falls.

Falling is a major health concern that has contributed significantly to older people's injury and loss of life (WHO, 2012). Among those aged 65 years and above, falls are the leading cause of morbidity and mortality (Kannus, Parkkari, Njemi \& Palvaren, 2005; NICE, 2015). It is estimated that 424,000 older adults die from falls every year globally, of which over $80 \%$ are in developing countries (WHO, 2015). The prevalence of falls has been reported to be rising among older people in Nigeria (Adebiyi, Uchendu, Ikotun, Oluleye, \& Olukotun, 2009; Bekibele \& Gureje, 2010). We speculate that the higher percentage of fatal injuries from falls in developing countries may be due in part to a lack of fall prevention strategies.

Fall prevention strategies, either in single or multifactorial interventions, have contributed immensely to the reduction of falls in developed countries (Campbell et al., 1997; Formosa, Brenda, Fawcett, Burke \& O’leary, 2014; Jensen, JLundin-Olsson, Nyberg, \& Gustafson, 2003; Skelton, Dinan, Campbell, \& Rutherford, 2005). A meta-analysis of randomised controlled trials (17 articles) showed that falls resulting in fractures were reduced by $61 \%$ among communitydwelling older adults when fall prevention exercise programmes were implemented (El-Khoury et al., 2013). In peer-reviewed literature, we identified only one fall prevention strategy in 
Africa (South African falls prevention strategy; Kalula, 2007). We were unable to find any published evidence that the strategy has been translated into clinical settings within the South African context, let alone other African countries (Kalula, 2007).

Fall prevention strategies are typically implemented by teams made up of geriatricians, physiotherapists and occupational therapists (NICE, 2015). These professionals work as a team from the design to the delivery of a fall prevention strategy into the explicit evaluation of the adoption of such strategies in clinical settings (Formosa et al., 2014). Exercise as a single fall prevention strategy has been successful in fall prevention (Cameron et al., 2012; Choi \& Kim, 2015; Faber, Bosscher, Chin, \& Van Wieringen, 2006). Exercise prescription targeted towards fall prevention is within the scope of practice of physiotherapists. However, little has been written about physiotherapists' contributions in falls prevention in developing nations like Nigeria. Also, understanding the falls prevention knowledge and practice among Nigerian physiotherapists is crucial in implementing effective falls prevention programmes in Nigeria and may contribute to knowledge translation in other countries in the developing world (Laing, Silver, York, \& Phelan, 2011). Therefore, this study sought to determine the levels of knowledge and practice of physiotherapists in Nigeria on fall prevention among older adults.

\section{METHODS}

\section{Study Design and Participants}

The study was a cross-sectional descriptive study that utilised probability sampling. The prospective participants for this study were physiotherapists licensed to practice in Nigeria according to the 2013 Medical Rehabilitation Therapist Board of Nigeria (MRTB) annual bulletin 
(MRTB, 2013). From the listed physiotherapists in the MRTB bulletin ( $n=2,239)$, we aimed for a sample size of 329 participants; this was needed to estimate a 95\% confidence level and margin of error of $5 \%$ for all questions with two answers (Bryman, 2012), assuming we achieved $80 \%$ response (Akinpelu \& Eluchie, 2006; Oyeyemi \& Oyeyemi, 2011).

Sampling was conducted in two stages. First, we randomly selected three states from each of the six geopolitical zones resulting in 18 selected states. Second, a list of licenced physiotherapists in each of the 18 selected states was created, the list entries were numbered, and subsequently, we systematically selected prospective participants for the study $(n=400)$. Research assistants (RAs) recruited from each of the 18 states received document sets (participant information sheets, informed consent forms, and questionnaires) for each of the selected prospective participants. Participants who gave informed consent proceeded to fill out the questionnaire and returned them in a sealed envelope to ensure confidentiality. Although the target sample size was 329,400 document sets were distributed to adjust for an estimated 20\% non-response rate (Oyeyemi \& Oyeyemi, 2011). Questionnaires not properly filled out were excluded from the study.

\section{Instrument}

We adapted a questionnaire developed by Peel, Brown, Lane, Milliken, and Patel (2008) and Brown,Gottschalk, Van Ness, Fortimky, and Tinet (2005) (see appendix 1). We modified some of the questions to suit the cultural context and subsequently added some questions informed by literature on falls and fall prevention (Avin et al., 2015; Stenberg \& Wann-Hansson 2011; Todd \& Skelton, 2004). We determined the psychometric properties of the questionnaire through validity (face, content and factor extraction) and reliability testing. The content and 
face validity of this questionnaire were addressed through a review by 6 physiotherapists with at least 5 years of research experience in questionnaire development. We revised the wording of the questions and answer options following each of two rounds of review. The resulting modified questionnaire was used for reliability testing among 18 randomly selected physiotherapists in Nigeria at 2-week intervals. We obtained an intraclass correlation coefficient of 0.94 , implying that the instrument shows high stability over a period of time (Kumar, 2005). We performed factor analysis on the questions on the questionnaire, using principal axis factoring with direct oblimin rotation, from which we found 2 strong factors (eigenvalues of 3.69 and 2.18). Factor loading ranged from 0.70 to 0.86 and 0.68 to 0.82 on the 2 factors. The two factors identified were practice (factor 1 ) and knowledge (factor 2 ) questions, which were group into two scales, with Cronbach's alpha of 0.81 and 0.75 respectively.

From the above process, a three-section 25 -item questionnaire was developed. Section $\mathrm{A}$ obtained the socio-demographic information. In Section B, participants were asked about how long they spend with patients who are older adults, and how often they practised specific elements of fall prevention, on a Likert scale ranging from Never (1) to Always (5). In Section C, participants were asked about their knowledge on the WHO fall prevention strategy or any other fall prevention strategy. Their knowledge of possible interventions and the possible risk factors for falls among older people were also ranked by level of importance on a Likert scale ranging from Not very important (1) to Very important (5). 


\section{Scoring of items in the questionnaire}

Responses measuring level of reported practice were scored 1,2,3,4 or 5 representing: never, rarely, sometimes, often or always, respectively. Each of the scores were re-coded: never and rarely as 1 (low practice level); sometimes as 2 (moderate practice level); and often and always as 3 (high practice level). Six questions measured practice and the total score was calculated and classified as: low level of practice (scores less than 6, representing raw score sums of less than 12); moderate level of practice (scores 7-12, representing raw scores sums of 13-18 in which all item scores were 2 or 3, with at least one item score being 3); or high level of practice (scores 13-18, representing raw scores sums of 19-30, in which most of the item scores were 4 or 5).

Responses measuring knowledge were scored 1,2,3,4 or 5 representing: not very important, not important, moderately important, somewhat important, or very important, respectively. Each of the scores were re-coded: not very important and not important as 1 (low knowledge level); moderately important as 2 (moderate knowledge level); and somewhat important and very important as 3 (high knowledge level). Eight questions measured knowledge about risk factors and the total score was calculated and classified as: low level of knowledge (scores less than 8 , representing raw score sums less than 16); moderate level of knowledge (scores 9-16, representing raw scores sums of 17-24 in which all item scores were 2 or 3 , with at least one item score being 3); or high level of knowledge (scores 16-24, representing raw scores sums of 25-40, in which most item scores were 5 or 4 ). 


\section{Data analysis}

Descriptive statistics were calculated for all socio-demographic characteristics and scores. Cross tabulation, chi-square and non-parametric ANOVA (Kruskal-Wallis) tests were used to examine if there were associations between socio-demographic characteristics and the levels of knowledge and practice of physiotherapists in Nigeria about preventing falls among older people. All tests were conducted using a 95\% confidence level, unless otherwise stated. All data were analysed using SPSS software version 23.

\section{RESULTS}

Of the 329 physiotherapists who were intended to receive questionnaires, 248 participants returned questionnaires: a response rate of $75 \%$. Fourteen questionnaires did not have sufficiently complete data for analysis, leaving 237 valid for analysis. Table 1 shows demographic information about the participants. Almost all participants $(n=230,97 \%)$ reported that they have treated older adults at least once in their practice with an average treatment time of 60 minutes per visit.

Overall, participants in our study have high levels of knowledge (median score $=22$ ) and reported practice (median score $=14$ ) about preventing falls among other adults. Most of the participants had a high level of knowledge $(n=211,89 \%)$ while $24(10.1 \%)$ and $2(0.8 \%)$ of the participants had a moderate and low level of knowledge respectively. Similarly, 151 (63.7\%) of participants reported a high level of fall prevention practice, $80(33.7 \%)$ and $6(2.6 \%)$ of participants reported a moderate and low level of practice, respectively. A high percentage 
$(79.3 \%, n=188)$ of the participants reported not being aware of the WHO fall prevention or any other fall prevention strategy.

Table 2 shows results for individual items about participants' knowledge of risk factors for falls. Among these items, the participants' knowledge on whether multiple medications were a risk factor for falls was moderate in contrast to all of the other risk factors listed for which participants' knowledge was generally high. Table 3 shows results for individual questions about participants' reported practice. Participants showed a moderate level of practice on documenting and planning for treatment on the risk factors that could predispose older people to fall, and a low level of practice in referring older people to other professionals for fall prevention and management. Only 184 participants listed possible conditions (either medical, mental or physical) that could make older adults more prone to falls; of which 91 participants listed stroke, whereas the remaining participants listed cognitive impairment $(n=32)$, osteoarthritis ( $n=22)$, alcoholism ( $n=16)$, rheumatoid arthritis $(n=8)$, lower limb fracture $(n=8)$, Visual disorder $(n=3)$, poor posture $(n=2)$, and hearing deficit $(n=2)$.

Figure 1 shows what participants identified as possible fall intervention strategies. A high percentage of the participants identified balance training (85.6\%), strengthening exercises (78.8\%), and education (75.8\%) as the possible interventions for fall prevention among older people.

The Kruskal-Wallis test showed that age and years of experience had no association with the levels of knowledge and practice; Chi-square test showed that gender, highest qualification, and work setting also had no association with the levels of knowledge and practice (table 1). 


\section{DISCUSSION}

The aim of the study was to determine the levels of knowledge and reported practice of physiotherapists in Nigeria on fall prevention among older adults using a cross-sectional survey method. We found that the overall levels of knowledge and reported practice were generally high except that most of the physiotherapists in Nigeria we surveyed were not familiar with the WHO fall prevention framework. We first consider the extent to which our sample was representative of physiotherapists in Nigeria, and then discuss our findings in relation to others in the literature. The predominance of male physiotherapists, and reported work setting as a tertiary institution like a federal teaching hospital, in our sample was consistent with other reports of the Nigerian physiotherapy workforce (Akinpelu \& Eluchie, 2006; Ibikunle, Kalu \& Useh, 2013; Oyeyemi \& Oyeyemi, 2011). The high proportion of participants who were under 30 years of age was not surprising considering how there has been rapid growth in recent years in the size and quantity of physiotherapy education programs in Nigeria. Therefore, we consider that the sample was somewhat representative of the Nigerian physiotherapy workforce.

The finding that the overall levels of knowledge and practice reported by physiotherapists in Nigeria on preventing falls among older people were high is consistent with studies on knowledge and practice among healthcare professionals in other countries (Kamunge, 2013; Parmeggiani, Abbate, Marinelli, \& Angelillo, 2010), but is in contrast with a study based in the USA that reported that only $38 \%$ of the employees of a state department of health working with older adults felt very knowledgeable about fall prevention practices (Laing et al., 2011). Physiotherapists in our study showed a moderate knowledge of multiple medications as risk factors for falls, compared to the physiotherapists in the USA that showed a high level of 
knowledge of multiple medications as a risk factor for falls (Brown et al., 2005). This difference could be attributed to the multidisciplinary training and practice patterns of physiotherapists in the USA. Multidisciplinary training was not historically strong in Nigeria, although it is a growing culture in healthcare practices and training in Nigeria. In addition, balance training was selected as the most commonly practiced fall prevention intervention by physiotherapists in Nigeria, and this is consistent with a previous study conducted among physiotherapists in the USA (Brown et al., 2005). Furthermore, 10 of the 12 fall prevention interventions were selected by over half of participants, implying that the physiotherapists in Nigeria are aware of the interventions used in fall preventions.

Surprisingly, our results revealed that most physiotherapists did not know about the WHO fall prevention strategy or any other standardised fall prevention strategy. Nevertheless, most reported a high level of the knowledge on some components of fall prevention. We speculate that physiotherapists in Nigeria have high knowledge of fall prevention for special populations such as people with stroke and may have applied this knowledge to older people more generally. Also, the low awareness of standardized fall prevention strategies could be attributed to the lack of emphasis on models, frameworks and theories in most healthcare professional training in developing countries (Davis, 2006). Most physiotherapists in Nigeria may therefore not have learned theories behind fall prevention strategies, but instead have practical knowledge based on experience.

Physiotherapists in Nigeria reported a moderate level of practice with respect to documenting and planning treatment for risk factors. This finding is in contrast with various reports that enumerate how physiotherapists in developed countries have advanced to the level of 
documenting and planning treatment for older people with 3-4 risk factors for falls (Avin et al., 2015; Dhanak \& Penhall, 2014; Peel et al., 2008). Furthermore, physiotherapists in Nigeria reported a low level of practice on referring older people to any other healthcare professionals for fall prevention. A little over half of the physiotherapists (50.6\%) reported never or rarely referring patients to any other professionals for fall prevention; this finding contrast with the finding that only $13 \%$ of physiotherapists in a USA study reported "almost never or never" to a question about referring patients to other health professionals (Peel et al., 2008). However, our results resonate with a study in South Africa that showed a low level of referral between professions with respect to falls in older adults (Kalula, De Villers, \& Ferreria, 2006). There are many reasons that may contribute to the low level of referrals about fall prevention in Nigeria and South Africa, potentially: lack of referral culture, not having enough specialised professionals to whom they could refer patients, or lack of fall clinics.

None of the demographic or practice factors examined in this study were associated with levels of knowledge and practice of falls prevention among physiotherapists in Nigeria. This finding is partially consistent with findings in the literature. Age and gender did not appear to influence the levels of knowledge and practice of fall prevention, consistent with findings from a study in the USA (Brown et al., 2005). In contrast, years of experience as a physiotherapist showed no significant association, unlike findings in other reports in which more experienced healthcare professionals typically were reported to have a higher knowledge and practice of the subject matter (Brown et al., 2005; Kamunge, 2013; Sanzero, Weber \& Wang 2003). Similarly, the facility of practice (care setting) showed no significant association with the levels of knowledge or practice, unlike findings reported by others (Koh, Manias, Hutchinson, Donath, \& Johnston, 
2003; Oliver et al., 2007), but this may be a consequence of having a high number of categories for this variable.

\section{Implications for physiotherapy practice}

Although physiotherapists in Nigeria generally showed high levels of knowledge and practice about fall prevention in older adults, there is room for improvement in their knowledge and practice with respect to standardised, multidisciplinary approaches to fall prevention, and the importance of case note documentation. Knowledge translation (KT) strategies are needed such as updating standards of practice, creating clinical practice guidelines, and then using methods of reminder, audit and feedback to ensure that practice patterns are appropriately changed to reflect best practice. However, the high level of knowledge implies that fall prevention strategies could be sustainably implemented in most physiotherapy clinical practice settings in Nigeria, because a high level of knowledge has been shown to be a predictive factor for the successful implementation of fall prevention clinical practice guidelines among healthcare professionals (Koh et al., 2008).

There are also implications for physiotherapy practice in other countries. Nigeria is the most populous country in Africa and has more physiotherapists than any other African country except Egypt and South Africa (World Confederation for Physical Therapy, 2018). Many physiotherapists in Nigeria desire to emigrate to developed countries (Oyeyemi et al.,2012; Ibikunle et al. 2013). The findings in this study imply that these Nigerian physiotherapists may have appropriately high knowledge and practice about fall prevention in older adults to be wellprepared for employment in developed countries with ageing populations. 


\section{Limitations}

There may have been sampling error or bias, even though random sampling was employed; for example, physiotherapists uninterested in care of older adults may have declined to return the questionnaire. There may also have been biases associated with Likert scale questions that may have influenced the results in this study (Michalos, McDonald, \& Kahlke, 2009). In addition, our evidence for the validity of the instrument is limited to face and content validity and the factor analysis, and it would have been stronger if we had other objective evidence for its validity. Furthermore, our questionnaire with closed-ended questions captured only some aspects of practice and knowledge; moreover, the questionnaire would have worked better if we had placed some questions earlier. For instance, question 22 in the questionnaire should have come before questions 20 and 21 in which case it would have added value to the testing of knowledge on falls. Furthermore, the absence of a qualitative component to further explore in detail the perceived knowledge and practice is a limitation to this study. Therefore, further research would be needed to confirm the levels of knowledge and practice, using techniques such as examining answers to open-ended questions, direct observations of physiotherapists in clinical settings, or reviewing clinical records written by physiotherapists.

We conclude that physiotherapist in Nigeria generally showed high overall levels of knowledge and reported practice in preventing falls among older people but have low level of awareness about standardised fall prevention strategies such as WHO and low level of practice on referring older people who have risk of falls to other healthcare professionals for further assessment or management. 


\section{REFERENCES}

Adebiyi, O., Uchendu, O., Ikotun, O., Oluleye, O., \& Olukotun, P. (2009). Falls and outcomes amongst old people in rural dwellings. Annals of Ibadan Postgraduate Medicine, 7(2): 6-11.

Akinpelu, A. O., \& Eluchie, N. C. (2006). Familiarity with, knowledge and utilization of standardized outcome measures among physiotherapists in Nigeria. Physiotherapy Theory and Practice, 22, 61-67. doi.org/10.1080/09593980600564469

Avin, K., Hanke, T., Kirk-Sanchez, N., McDonough, M., Shubert, T., Hardage, J., \& Hartley, G. (2015). Management of falls in community-dwelling older adults: Clinical Guidance Statement from the Academy of Geriatric Physical Therapy of the American Physical Therapy Association. Physical Therapy, 95,815-834. doi: 10.2522/ptj.20140415

Bekibele, C., \& Gureje, O. (2010). Fall incidence in a population of elderly persons in Nigeria. Gerontology, 56,278-283. doi: 10.1159/000236327

Brown, C., Gottschalk, M., Van Ness, P., Fortimky, H., \& Tinet, H. (2005). Changes in physical therapy providers' use of fall prevention strategies following a multicomponent behavioral change intervention. Physical Therapy, 85, 394-403. doi.org/10.1093/ptj/85.5.394

Bryman, A. (2012). Social Research Methods. $4^{\text {th }}$ edition. UK, Oxford University Press: Oxford.

Cameron, D., Gillespie, D., Robertson, M., Murray, R., Hill, D., Cumming, G., \& Kerse, N. (2012). Interventions for preventing falls in older people in care facilities and hospitals (Review). The Cochrane Collaboration and published in The Cochrane Library, Issue 12. Art. No.: CD005465 doi: 10.1002/14651858.CD005465.pub3.

Campbell, A. J., Robertson, M. C., Gardner, M. M., Norton, R. N., Tilyard, M. W., \& Buchner, D. M. (1997). Randomised controlled trial of a general practice programme of home based exercise to prevent falls in elderly women. British Medical Journal, 315, 1065-1069.

doi.org/10.1136/bmj.315.7115.1065

Choi, J., \& Kim, N. (2015). The effects of balance training and ankle training on the gait of elderly people who has fallen. Journal of Physical Therapy Science, 27, 139-142. doi: 10.1589/jpts.27.139

Davis, S. (2006). Rehabilitation: the use of theories and models in practice. UK, Elsevier Churchill: Living stone.

Dhanak, M., \& Penhall, R. (2014). Australian and New Zealand Society for Geriatric Medicine: Position Statement - Exercise guidelines for older adults. Australian Journal on Ageing, 33, 287-294. doi: 10.1111/ajag.12194 
El-Khoury, F., Cassou, B., Latouche, A., Aegerter, P., Charles, M., \& Dargent-Molina, F. (2015). Effectiveness of two year balance training programme on prevention of fall induced injuries in at risk women aged 75-85 living in community: Ossebo randomized controlled trial. British Medical Journal, 352,h3830. doi: 10.1136/bmj.h3830

Faber, M. J., Bosscher, R. J., Chin, A., \& Van Wieringen, P. (2006). Effects of exercise programs on falls and mobility in frail and pre-frail older adults: a multicenter randomized controlled trial. Archives of Physical Medicine and Rehabilitation, 87, 885-896. doi.org/10.1016/j.apmr.2006.04.005

Formosa, D., Brendan, B., Fawcett, C., Burke, C., \& O'Leary, J. (2014). Effectiveness of an evidence-based multidisciplinary falls prevention program in reducing falls in high-risk older people. Journal of the American Geriatrics Society, 62, 778-779. doi: 10.1111/jgs.12762

Ibikunle, P., Kalu, M., \& Useh, U. (2013). Professional motivation and plan amongst graduating Nigerian physiotherapy students. Journal of Human Ecology, 44,: 203-206. Doi.org/10.1080/09709274.2013.11906659.

Jensen, J., Lundin-Olsson, L., Nyberg, L., \& Gustafson, Y. (2003). Falls and injury prevention residential care-effects in residents with higher and lower levels of cognition. Journal of the American Geriatric Society, 51,627-635.

Kalula, S. (2007). Prevention of falls in older persons; Africa Case study. A WHO Global report on Falls among older persons. South Africa: WHO publication (Online) Available at http://www.who.int/ageing/projects/AFRO.pdf (Accessed on 16th May 2015).

Kalula, S., De Villers, L., \& Ferreria, K. (2006). Management of older patients presenting with falls to an Accident and Emergency department of a tertiary hospital: an audit. South African Medical Journal, 96, 718-721.

Kamunge, E. (2013). Exploring knowledge, attitude and practice of registered nurses regarding the spread of nosocomial infection, A PhD thesis, Seton Hall University. Available at eRespository paper 1865 (Online) http://scholarships.shu.edu/cgi/viewcontent.cgi?article=2872\&content=dissertation. (Accessed on $10^{\text {th }}$ August 2015).

Kannus, P., Parkkari, J., Niemi, S., \& Palvanen, M. (2005). Fall-induced deaths among elderly people. American Journal of Public Health Association, 95,422-424.

doi: 10.2105/AJPH.2004.047779 
Koh, S., Manias, E., Hutchinson, A., Donath, S., \& Johnston, L. (2008). Nurses' perceived barriers to the implementation of a fall prevention clinical practices guidelines in Singapore hospitals. BMC Health Services Research, 8,105. doi: 10.1186/1472-6963-8-105

Kumar, R. (2005). Research methodology: A step by step guide for beginners. London, SAGE publications.

Laing, S., Silver, I., York, S., \& Phelan, E. (2011). Fall prevention knowledge, attitude and practices of community stakeholders and older adults. Journal of Ageing, 10, 4061-4070. doi: $10.4061 / 2011 / 395357$

Medical Rehabilitation Therapist Board of Nigeria. (MRTB) 2013 List of licensed physiotherapist in Nigeria in 2012. Nigeria Medical Rehabilitation Therapy Board Bulletin, 13, 44-71.

Michalos, A., McDonald, C., \& Kahlke, H. (2009). Measuring knowledge, attitudes and behaviours towards sustainable development: Two exploratory studies. Canada: International Institute of Sustainable Development (IISD), institute for Social Research. (online) Available form: http://www.iisd.org/ (accessed on 4 June, 2015).

National Institute for Health and Care Excellence (NICE). (2015). Falls in older people. NICE quality standard (QS86). UK, NICE publication. (online) Available from http://www.nice.org.uk/guidance/qs68. (Accessed on $12^{\text {th }}$ August, 2015).

Oliver, D., Connelly, J., Victor, C., Shaw, F., Whitehead, A., Genc, Y.,... Margot, B. (2007). Strategies to prevent falls and fractures in hospitals and care homes and effect of cognitive impairment: Systematic review and meta-analyses. British Medical Journal, 334, 8285. doi: $10.1136 /$ bmj.39049.706493.55

Oyeyemi, A. \& Oyeyemi, L. (2011). Professional practice pattern and outlook of physiotherapists in Nigeria. Advances in Physiotherapy, 13: 162-169. doi: 10.3109/14038196.2011.609249

Oyeyemi, A., Oyeyemi, A., Maduagwu, S., Rufai, A., \& Aliyu, S.,(2012). Professional satisfaction and desire to emigrate among Nigerian Physiotherapists. Physiotherapy Canada, 64, 225-232. Doi:10.3138/ptc.2010-45.

Parmeggiani, C., Abbate, R., Marinelli, P., \& Angelillo, F. (2010). Healthcare workers and health care associated infections: Knowledge, attitudes and behaviour in emergency departments in Italy. BMC Infectious Diseases, 10, 5. doi: 10.1186/1471-2334-10-35

Peel, C., Brown, C., Lane, A., Milliken, E., \& Patel, K. (2008). A Survey of Fall Prevention Knowledge and Practice Patterns in Home Health Physical Therapists. Journal of Geriatric Physical Therapy, 31,64-70. 
Sanzero, L., Kleber, E., \& Wang, I. (2003). Research knowledge, attitude and practices of health professional. Nursing Outlook, 51, 165-170. doi.org/10.1016/S0029-6554(03)00112-X

Skelton D., Dinan, S., Campbell, M., \& Rutherford, O. (2005). Tailored group exercise (Falls Management Exercise-FaME) reduces falls in community-dwelling older frequent fallers (an RCT). Age Ageing, 34, 636-639. doi.org/10.1093/ageing/afi174

Stenberg, M., \& Wann-Hansson, C. (2011). Health care professionals' attitudes and compliance to clinical practices guidelines to prevent falls and fall injuries. Worldviews on Evidence-Based Nursing, 8, 87-95. doi: 10.1111/j.1741-6787.2010.00196.x

Todd, C., \& Skelton, D. (2004). What are the main risk factors for falls amongst older people and what are the most effective interventions to prevent these falls? A report for WHO Regional Office for Europe at the Health Evidence Network, Copenhagen. (Online) Available from http://www.euro.who.int/document/E82552.pdf, (Accessed 11 August, 2015)

United Nations. (2015). World Population Ageing 1950-2050 Population Division, DESA, United Nations. (Online) Available at http://www.un.org/esa/population/publications/worldageing19502050/ (Accessed on 03/11/2015).

World Confederation for Physical Therapy (WCPT) (2018). African Region of WCPT. (Online). Available from https://www.wcpt.org/africa. (Accessed on $6^{\text {th }}$ June, 2018).

World Health Organisation (WHO). (2012). Media Center: Facts sheet on Fall. (Online) Available from: http://www.who.int/mediacenter/factsheets/fs344/en/. (Accessed on $25^{\text {th }}$ January, 2014).

World Health Organisation (WHO). (2015). Media Center: Facts sheet on Falls. (Online) Available from: http://www.who.int/mediacentre/factsheets/fs344/en/. (Accessed on $25^{\text {th }}$ January, 2015). 


\section{Table 1}

Demographic characteritics and their relation to the level of knowledge and reported practice

\begin{tabular}{|c|c|c|c|}
\hline \multirow[t]{2}{*}{ Variable } & \multirow[t]{2}{*}{ Frequency (\%) } & \multicolumn{2}{|c|}{ Statistical test } \\
\hline & & Level of knowledge & Level of practice \\
\hline \multicolumn{4}{|l|}{ Age } \\
\hline \multicolumn{4}{|l|}{ (mean 31.3, SD 6.2 years) } \\
\hline 21-30 & $126(53.2)$ & & \\
\hline $31-40$ & $94(39.6)$ & $\mathrm{H}=0.950(p=0.813)$ & $1.919(p=0.589)$ \\
\hline $41-50$ & $14(5.9)$ & & \\
\hline$>50$ & $3(1.3)$ & & \\
\hline Total & $237(100)$ & & \\
\hline \multicolumn{4}{|l|}{ Gender } \\
\hline Male & $137(57.8)$ & & \\
\hline Female & $100(42.2)$ & $x^{2}=1.765(p=0.480)$ & $1.520(p=0.524)$ \\
\hline Total & $237(100)$ & & \\
\hline \multicolumn{4}{|l|}{ Highest qualification } \\
\hline Bachelors & $204(86.1)$ & & \\
\hline Postgraduate (MSc or Ph.D.) & $32(13.5)$ & $x^{2}=2.356(p=0.345)$ & $1.845(p=0.456)$ \\
\hline Higher National Diploma & $1(0.4)$ & & \\
\hline Total & $237(100)$ & & \\
\hline \multicolumn{4}{|l|}{ Work setting } \\
\hline Tertiary health care & $163(68.8)$ & & \\
\hline Secondary health care & $34(14.3)$ & & \\
\hline Specialist health care & $18(7.6)$ & & \\
\hline Private practice & $10(4.2)$ & $x^{2}=9.228(p=0.590)$ & $11.578(p=0.254)$ \\
\hline Primary health care & $7(3.0)$ & & \\
\hline Private hospitals & $5(4.2)$ & & \\
\hline Total & $237(100)$ & & \\
\hline \multicolumn{4}{|c|}{ Years of professional experience } \\
\hline$<1$ & $47(19.8)$ & & \\
\hline $1-5$ & $140(59.1)$ & & \\
\hline $6-10$ & $29(12.2)$ & $\mathrm{H}=0.666(p=0.881)$ & $1.737(p=0.629)$ \\
\hline$>10$ & 21 (8.9) & & \\
\hline Total & $237(100)$ & & \\
\hline
\end{tabular}


Table 2- Knowledge on risk factors for falls as identified by physiotherapists (frequencies and percentages)

\begin{tabular}{|c|c|c|c|c|c|c|}
\hline Item & High & & Mo & ate & Low & \\
\hline \multirow[b]{2}{*}{ Balance/gait disorder as a risk factor } & (n) & $(\%)$ & (n) & $(\%)$ & (n) & $(\%)$ \\
\hline & 215 & 90.7 & 13 & 5.5 & 9 & 3.8 \\
\hline Muscle weakness as a risk factor & 202 & 85.2 & 27 & 11.4 & 8 & 3.4 \\
\hline Environmental hazards as a risk factors & 172 & 72.6 & 45 & 19.0 & 20 & 8.4 \\
\hline Postural hypotension as a risk factors & 147 & 62.0 & 54 & 24.1 & 33 & 13.9 \\
\hline Sensory/perceptive deficit as a risk factors & 155 & 65.4 & 54 & 22.8 & 28 & 11.8 \\
\hline Multiple medications as a risk factors & 77 & 32.5 & 94 & 39.7 & 66 & 27.8 \\
\hline Impaired cognition & 168 & 70.9 & 46 & 19.4 & 23 & 9.7 \\
\hline Foot/foot wear problems as a risk factors & 167 & 70.5 & 43 & 18.1 & 27 & 11.4 \\
\hline
\end{tabular}

Notes: Percentages in bold reflect categories with highest percentages in each row. 
Table 3

Frequency and percentages of the individual items that measures the level of practice of physiotherapists on fall prevention among older people.

\begin{tabular}{|c|c|c|c|c|c|c|}
\hline \multirow[t]{2}{*}{ Item } & \multicolumn{2}{|c|}{ High } & \multicolumn{2}{|c|}{ Moderate } & \multicolumn{2}{|c|}{ Low } \\
\hline & (n) & $(\%)$ & (n) & $(\%)$ & (n) & $(\%)$ \\
\hline \multicolumn{7}{|l|}{ In your initial assessment, } \\
\hline $\begin{array}{l}\text { How often do you ask older people if they } \\
\text { have history of falls? }\end{array}$ & 134 & 56.5 & 83 & 35.0 & 20 & 8.4 \\
\hline $\begin{array}{l}\text { How often do you identify risks factors for } \\
\text { falls? }\end{array}$ & 118 & 49.8 & 88 & 37.1 & 31 & 13.1 \\
\hline $\begin{array}{l}\text { How often do you document risk factors for } \\
\text { falls? }\end{array}$ & 87 & 36.7 & 92 & 38.8 & 58 & 24.5 \\
\hline $\begin{array}{l}\text { How often do you document treatment plans } \\
\text { for risk factors? }\end{array}$ & 82 & 34.6 & 97 & 40.9 & 58 & 24.5 \\
\hline $\begin{array}{l}\text { How often do you refer older person to other } \\
\text { fall management team? }\end{array}$ & 49 & 20.1 & 68 & 28.7 & 120 & 50.6 \\
\hline $\begin{array}{l}\text { How often do you educate older person on } \\
\text { fall prevention? }\end{array}$ & 163 & 68.8 & 50 & 21.1 & 49 & 20.7 \\
\hline
\end{tabular}

Notes: Percentages in bold reflect categories with highest percentages in each row. 


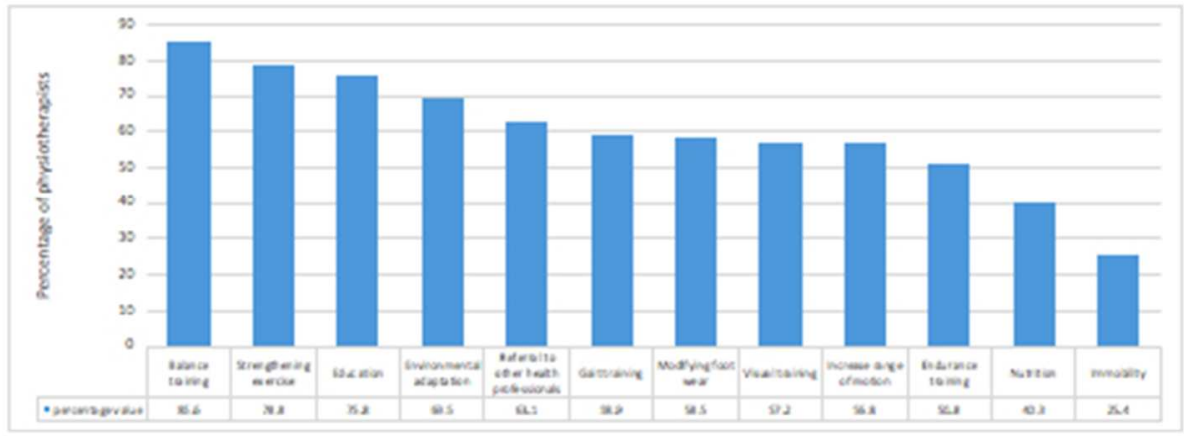

Figure 1: Percentages of the possibie fal prevention interventions identified by physlotherapists in Nigeria.

Percentages of the possible fall prevention interventions identified by physiotherapists in Nigeria.

$176 \times 78 \mathrm{~mm}(72 \times 72$ DPI $)$ 